\title{
FRANÇOIS VILLON
}

\section{ET SES LÉGATAIRES,}

\author{
PAR \\ $\therefore$ जis \\ AUGUSTE, LONGNON, \\ ARCHIVISTE AUX ARCHIVES NATIONALES
}

Extrait du tome II de la Romania.

PARIS,

LIBRAIRIE ALPHONSE LEMERRE, 27-29, PASSAGE CHOISEUL, 27-29

MAI 1873 